\title{
Smoking prevalence and effects on treatment outcomes in patients with tuberculosis
}

\author{
Kellyn Rocha de Vargas ${ }^{1}$, Alana Ambos Freitas² (1), \\ Ana Cláudia Vasconcellos Azeredo ${ }^{1} \mathbb{B}$, Denise Rossato Silva ${ }^{1,2 *}$
}

\section{SUMMARY}

OBJECTIVE: More than $20 \%$ of tuberculosis (TB) cases worldwide are attributable to smoking, and it is associated with an increased risk of latent and active TB, recurrence, and mortality. The aim of this study is to assess the smoking prevalence and the effects on treatment outcomes in TB patients.

METHODS: A prospective cohort study was conducted in patients with a recent TB diagnosis. The smoking status was defined, in addition to the patients' knowledge and attitudes toward smoking. The patients were followed up until the end of the treatment, and the treatment result was recorded.

RESULTS: Ninety-two patients were included in this study. The prevalence of active smoking was 31.5\%. Active smokers had less chance for cure $(62.1 \%$ versus $82.5 \% ; p=0.032)$ and more treatment dropout ( $31.0 \%$ versus $12.7 \% ; p=0.035)$ than non-active smokers. Patients demonstrated positive attitudes and good knowledge about smoking.

CONCLUSIONS: Active smokers had less chance for cure and more abandonment than non-active smokers. These results can be useful for the proper planning of actions that impact TB control, especially in the treatment results, such as cognitive-behavioral approaches to smoking cessation.

KEYWORDS: Tuberculosis. Smoking. Knowledge. Prevalence. Smoking cessation.

\section{INTRODUCTION}

Tuberculosis (TB) is an important public health problem worldwide, particularly in low- and middle-income countries. Brazil is among the 30 countries with the highest TB burden, which is responsible for $87 \%$ of TB cases globally, with a cumulative incidence of 44 cases/100,000 inhabitants in $2018^{1}$.

Among the various risk factors for TB, smoking was identified as a serious aggravating factor, especially in developing countries. Both active and passive smoking considerably increase the risk of falling ill and dying from TB. It is estimated that more than $20 \%$ of TB cases worldwide are attributable to smoking ${ }^{1}$. The influence of smoking on TB is explained by the dysfunction of ciliary mechanics, a decrease in the immune response of an individual, the number of macrophages, and a decrease in the levels of CD4 and CD8 cells, thus increasing susceptibility to infection by Mycobacterium tuberculosis ${ }^{2}$.

Tobacco use is one of the most important public health issues worldwide. Currently, almost 6 million people consume

\footnotetext{
'Universidade Federal do Rio Grande do Sul, Programa de Pós-Graduação em Ciências Pneumológicas - Porto Alegre (RS), Brazil.

¿Universidade Federal do Rio Grande do Sul, Faculdade de Medicina - Porto Alegre (RS), Brazil.

*Corresponding author: denise.rossato@terra.com.br

Conflicts of interest: the authors declare there is no conflicts of interest. Funding: none.

Receveid on September 24, 2020. Accepted on November 27, 2020.
} 
tobacco each year, both for direct use of the product and for secondhand smoke. By 2020, the number of tobacco deaths will increase to 7.5 million, representing $10 \%$ of all deaths. In addition, smoking is associated with a significant increase in the risk of latent TB infection, active TB, TB recurrence, and TB mortality ${ }^{3}$.

Therefore, considering that Porto Alegre is the Brazilian capital with the highest number of smokers (24.6\% of males and $20.9 \%$ of females $)^{4}$, which is the fourth capital city with the highest number of TB cases in Brazil ${ }^{5}$, the aim of this study is to assess the prevalence of smoking and the effects on treatment outcomes in TB patients.

\section{METHODS}

\section{Study design and location}

A prospective cohort study was conducted to assess the prevalence of smoking and its effects on treatment outcomes for patients diagnosed with TB treated at the Tuberculosis Reference Center of the District Management Glória-Cruzeiro-Cristal in the city of Porto Alegre, RS, Brazil. The study was approved by the Ethics Committee of the Municipality of Porto Alegre on January 30, 2018 (number: CAAE 81741418.7.0000.5338). All patients signed a written informed consent form before participating in this study.

\section{Population and data collection}

The study population consisted of patients with a recent diagnosis (i.e., maximum 30 days) of pulmonary $\mathrm{TB}$, who were evaluated at the Tuberculosis Reference Center of the District Management Glória-Cruzeiro-Cristal. This study included patients aged 18 years or above, who were diagnosed as pulmonary TB cases according to consensus criteria $^{6}$. Patients who refused to sign the written informed consent form were excluded.

A standardized form was filled out for each patient, with the demographic data, symptoms, smoking, alcohol and drug use, comorbidities, and TB diagnostic tests. The treatment outcome (e.g., cure, dropout, failure, and death) was also recorded.

Smoking status was determined according to the definitions of the Centers for Disease Control and Prevention (CDC) ${ }^{7}$. An active smoker was defined as one who smoked at least 100 cigarettes in his lifetime, and at the time of the survey he was smoking at least 1 day a week. An ex-smoker was defined as one who smoked at least 100 cigarettes in his lifetime, but who at the time of the study did not smoke anymore. That patient who smoked less than 100 cigarettes in his lifetime was considered a nonsmoker.
In addition to the smoking history, the phase in the cessation process in which the patient was found was identified, according to the stages of behavioral change described by Prochaska and Di Clemente (e.g., pre-contemplation, contemplation, preparation, action, maintenance, or relapse) ${ }^{8}$.

The level of nicotine dependence was also assessed by using the Fagerström scale. This scale classifies the degree of dependence on smoking as follows: very low, low, medium, high, and very high. Patients' knowledge and attitudes toward smoking were also assessed. For this, a questionnaire was developed based on the earlier studies ${ }^{9-11}$, in which the first part contains 10 questions (true/false) on knowledge about smoking and the tobacco-tuberculosis relationship and the second part contains 10 questions (e.g., the Likert scale) on attitudes toward smoking. The first part of the questionnaire was answered by all patients included in this study, and the second part was answered only by active smokers and ex-smokers. The questionnaire was pretested with 20 patients before the start of this study, and the results are described in Tables 1 and 2 (see also "Results" section).

\section{Statistical analysis}

The data analysis was performed using SPSS 18.0 (Statistical Package for the Social Sciences, Chicago, IL, USA). The data were presented as number of cases, mean \pm standard deviation $(\mathrm{SD})$, and median with interquartile range (IQR). Categorical comparisons were performed by the chi-squared test using Yates's correction if indicated or by the Fisher's exact test. Continuous variables were compared using the $t$-test or Wilcoxon test. A two-sided $\mathrm{p}<0.05$ was considered significant for all the analyses.

Considering the prevalence of active smokers among $\mathrm{TB}$ patients in an earlier study of approximately $40 \%$, with a $95 \%$ confidence interval (CI) and a CI amplitude of 0.20 , it will be necessary to include 92 patients.

\section{RESULTS}

During this study period, 92 patients were included. The prevalence values of active smokers, ex-smokers, and nonsmokers were $31.5 \%(\mathrm{n}=29), 22.8 \%(\mathrm{n}=21)$, and $45.7 \%$ $(n=42)$, respectively. Table 3 describes the characteristics of active smokers compared with those of non-active smokers (ex-smokers and never smokers). Active smoking patients were more often males (75.9\% versus $49.2 \%$; $\mathrm{p}=0.0016)$ and drug users $(62.1 \%$ versus $11.1 \%$; $\mathrm{p}<0.0001)$ compared with non-active smoking patients. The positive sputum smear microscopy was more frequent in active smoking 
Table 1. Knowledge of patients regarding smoking.

\begin{tabular}{l|c|c}
\hline Affirmative & True (\%) & False (\%) \\
\hline Smoking is addictive & $90(97.8)$ & $2(2.2)$ \\
\hline Smoking is a disease & $78(84.8)$ & $14(15.2)$ \\
\hline Smoking has the greatest negative effect on the vascular system & $86(93.5)$ & $6(6.5)$ \\
\hline $\begin{array}{l}\text { "Smoker's cough," a type of chronic bronchitis, is caused by irritation of the lungs } \\
\text { and bronchi and due to chemicals in the cigarette }\end{array}$ & $92(100.0)$ & 0 \\
\hline $\begin{array}{l}\text { Dangers from cigarette smoking increase with dose (number of cigarettes smoked, } \\
\text { number of years a person smoked, and amount of smoke inhaled) }\end{array}$ & $89(96.7)$ & $3(3.3)$ \\
\hline Smoking affected your health & $85(92.4)$ & $7(7.6)$ \\
\hline Smokers are at increased risk of tuberculosis & $85(92.4)$ & $7(7.6)$ \\
\hline Smokers are at higher risk of having tuberculosis more than once & $84(91.3)$ & $8(8.7)$ \\
\hline $\begin{array}{l}\text { Smokers with tuberculosis are more likely to spread the tuberculosis bacillus than } \\
\text { nonsmokers with tuberculosis }\end{array}$ & $86(93.5)$ & $6(6.5)$ \\
\hline Smokers with tuberculosis are at higher risk of death than nonsmokers & $86(93.5)$ & $6(6.5)$ \\
\hline
\end{tabular}

Table 2. Attitudes of patients toward smoking.

\begin{tabular}{l|c|c|c|c|c}
\hline Affirmative & Totally agree & Agree & Not sure & Disagree & Totally disagree \\
\hline Smoking is fun & 0 & $22(44.0)$ & $2(4.0)$ & $26(52.0)$ & 0 \\
\hline People smoke just to show off & 0 & $27(54.0)$ & $3(6.0)$ & $20(40.0)$ & 0 \\
\hline Smoking calms your nerves & $1(2.0)$ & $43(86.0)$ & 0 & $6(12.0)$ & 0 \\
\hline Smoking makes you smelly & $2(4.0)$ & $46(92.0)$ & 0 & $2(4.0)$ & 0 \\
\hline Smoking is a waste of money & $2(4.0)$ & $45(90.0)$ & 0 & $3(6.0)$ & 0 \\
\hline Smoking makes you relieve all life stresses & $1(2.0)$ & $30(60.0)$ & 0 & $19(38.0)$ & 0 \\
\hline Smoking keeps your weight down & 0 & $36(9.2)$ & 0 & $14(28.0)$ & 0 \\
\hline Smoking gives you confidence & 0 & $21(42.0)$ & 0 & $29(58.0)$ & 0 \\
\hline $\begin{array}{l}\text { Smoking should be allowed at fewer } \\
\text { places than it is now }\end{array}$ & $1(2.0)$ & $42(84.0)$ & $2(4.0)$ & $5(10.0)$ & 0 \\
\hline Sales of cigarettes should be outlawed & $2(4.0)$ & $39(78.0)$ & 0 & $9(18.0)$ & 0 \\
\hline
\end{tabular}

patients (89.7 versus $66.7 \% ; \mathrm{p}=0.020)$. Regarding treatment outcomes, active smoking patients were less cured (62.1 versus $82.5 \% ; \mathrm{p}=0.032$ ) and had more treatment dropout (31.0 versus $12.7 \% ; \mathrm{p}=0.035)$ than non-active smoking patients.

Among smokers, the degree of dependence measured by using the Fagerström scale was as follows: very low $(\mathrm{n}=2$; 6.9\%), low $(\mathrm{n}=6 ; 20.7 \%)$, medium $(\mathrm{n}=5 ; 17.2 \%)$, high $(\mathrm{n}=11 ; 37.9 \%)$, and very high $(\mathrm{n}=5 ; 17.2 \%)$. With regard to the stages of behavioral change, smoking patients were distributed as follows: pre-contemplation $(\mathrm{n}=8 ; 27.6 \%)$, contemplation $(\mathrm{n}=16 ; 55.2 \%)$, and preparation $(\mathrm{n}=5 ; 17.2 \%)$. Table 1 shows the results for the patients' knowledge regarding smoking, and Table 2 shows the results for the patients' attitudes toward smoking.

\section{DISCUSSION}

In this cohort study, we found a prevalence of active smoking of $31.5 \%$ in TB patients. In addition, active smoking patients had less chance for cure and had more treatment dropout than non-active smoking patients.

There are several studies showing that smoking is strongly linked to TB, and a considerable proportion of the global TB burden can be attributed to smoking. A large proportion of TB patients can be active smokers or be exposed to other people's tobacco smoke ${ }^{12-15}$. In this study, we found that a prevalence of active smoking was $31.5 \%$ in TB patients. In a study conducted in Malaysia ${ }^{9}$, the prevalence of active smoking was $40.27 \%$ among TB patients. Wang et al. ${ }^{12}$ reported in a casecontrol study an even higher prevalence in China (54.6\%). In a 
Table 3. Characteristics of active smokers and nonactive smokers.

\begin{tabular}{|c|c|c|c|}
\hline Characteristics & $\begin{array}{c}\text { Active } \\
\text { smokers } \\
(n=29)\end{array}$ & $\begin{array}{c}\text { Non- } \\
\text { active } \\
\text { smokers } \\
(n=63)\end{array}$ & p-value \\
\hline \multicolumn{4}{|c|}{ Demographic data } \\
\hline \multicolumn{4}{|l|}{ Age } \\
\hline Male sex & $22(75.9)$ & $31(49.2)$ & 0.016 \\
\hline White race & $19(65.5)$ & $34(54.0)$ & 0.298 \\
\hline \multicolumn{4}{|l|}{ Symptoms } \\
\hline Cough & $28(96.6)$ & $54(85.7)$ & 0.162 \\
\hline Fever & $15(51.7)$ & $31(49.2)$ & 0.822 \\
\hline Weight loss & $25(86.2)$ & $52(82.5)$ & 0.768 \\
\hline Alcohol abuse & $5(17.2)$ & $6(9.5)$ & 0.313 \\
\hline Drug use & $18(62.1)$ & $7(11.1)$ & $<0.0001$ \\
\hline HIV & $14(48.3)$ & $20(31.7)$ & 0.127 \\
\hline $\begin{array}{l}\text { Smear-positive } \\
\text { sputum }\end{array}$ & $26(89.7)$ & $42(66.7)$ & 0.020 \\
\hline Positive culture & $20(69.0)$ & $44(69.8)$ & 0.932 \\
\hline \multicolumn{4}{|c|}{ Treatment outcomes } \\
\hline Cure & $18(62.1)$ & $52(82.5)$ & 0.032 \\
\hline Dropout & $9(31.0)$ & $8(12.7)$ & 0.035 \\
\hline Death & $2(6.9)$ & $3(4.8)$ & 0.649 \\
\hline
\end{tabular}

study conducted in $\operatorname{Iran}^{16}$, with patients with a recent diagnosis of $\mathrm{TB}$, the authors demonstrated that $20.2 \%$ of the patients were daily smokers, $1.8 \%$ were occasional smokers, and $8.9 \%$ had quit smoking before TB diagnosis.

Increasing evidence suggests that smoking is significantly associated with treatment failure, dropout, and death ${ }^{17-19}$. In this study, smoking patients had less chance for cure and had more treatment dropout when compared to non-active smoking patients. A similar study that evaluated 183 smokers and 151 nonsmokers showed that the cure rates were higher in nonsmoking patients and in those who stopped smoking in the first 2 months of TB treatment, compared to smoking patients ${ }^{20}$. Dujaili et al. ${ }^{21}$ performed a logistic regression analysis in a retrospective cohort study on the effects of tobacco on TB treatment outcomes and reported better results in nonsmokers than in smokers (odds ratio [OR] 0.312, 95\%CI 0.17-0.57). El Sony et al. ${ }^{22}$ also found a significant difference between treatment outcomes in the group who stopped smoking compared to the group of smokers.

In a cross-sectional study, more than $30 \%$ of smoking patients with TB revealed that they had never been asked about their smoking habits or were advised to stop smoking ${ }^{23}$. This approach to smoking in TB patients has been strongly recommended ${ }^{24}$. Likewise, understanding the knowledge and attitudes of TB patients about smoking is important to guide the development of effective educational interventions. In general, in this study, patients demonstrated good knowledge about smoking and positive attitudes against tobacco use. However, $88 \%$ of patients reported that "smoking calms your nerves" and more than $60 \%$ stated that "smoking relieves all life stresses." These findings alert to the need for cognitive-behavioral assessment and investigation of psychiatric comorbidities, such as anxiety and depression.

This study has some limitations. First, it was carried out in a single Health Unit. However, we believed that the results found in this study are applicable to places with similar characteristics. In addition, smoking status was self-reported and was not confirmed by biological measurements, such as the determination of carbon monoxide in exhaled air. Although the self-report of smoking status is strongly correlated with biochemical confirmation in the observational studies ${ }^{25}$, underreporting of tobacco use may occur.

\section{CONCLUSIONS}

More than $30 \%$ of TB patients were active smokers in this study. In addition, active smoking patients were less cured and had more treatment dropout than non-active smoking patients. These results can be useful for the proper planning of actions that have an impact on TB control, especially on treatment outcomes, such as cognitive-behavioral approaches to smoking cessation.

\section{AUTHORS" CONTRIBUTIONS}

KRV: Conceptualization, Data curation, Investigation, Methodology, Project administration, Writing the original draft. AAF: Conceptualization, Investigation, Methodology, Writing - editing and review. ACVA: Conceptualization, Investigation, Methodology, Writing - editing and review. DRS: Conceptualization, Data curation, Investigation, Methodology, Project administration, Supervision, Writing original draft. 


\section{REFERENCES}

1. World Health Organization. Global tuberculosis report 2019. [Internet]. Available from: https://apps.who.int/iris/ bitstream/handle/10665/329368/9789241565714-eng. pdf? sequence $=19$ \&isAllowed $=y$.

2. van Zyl Smit RN, Pai M, Yew WW, Leung CC, Zumla A, Bateman ED, et al. Global lung health: the colliding epidemics of tuberculosis, tobacco smoking, HIV and COPD. Eur Respir J. 2010;35(1):2733. https://doi.org/10.1183/09031936.00072909

3. Kowada A. Cost-effectiveness of tobacco cessation support combined with tuberculosis screening among contacts who smoke. Int J Tuberc Lung Dis. 2015;19(7):857-63. https://doi. org/10.5588/ijtld.14.0518

4. Brasil. Ministério da Saúde. Instituto Nacional de Câncer. Tabagismo [Internet]. 2018. Available from: https://www. inca.gov.br/tabagismo

5. Ministério da Saúde. Secretaria de Vigilância em Saúde. Boletim Epidemiológico. Implantação do Plano Nacional pelo fim da tuberculose como problema de saúde pública no Brasil: primeiros passos rumo ao alcance das metas [Internet]. Brasília: Ministério da Saúde; 2018 [citado 2018 mar]. Available from: https://antigo.saude.gov.br/images/pdf/2018/ marco/26/2018-009.pdf.

6. Conde MB, Melo FAF, Marques AMC, Cardoso NC, Pinheiro VGF, Dalcin PTR, et al. III Brazilian thoracic association guidelines on tuberculosis. J Bras Pneumol. 2009;35(10):1018-48. https:// doi.org/10.1590/s1806-37132009001000011

7. Centers for Disease Control and Prevention. National Center for Health Statistics. General concepts [Internet]. 2020. Available from: https://www.cdc.gov/nchs/nhis/tobacco/tobacco_glossary.htm.

8. Prochaska JO, DiClemente CC. Stages and processes of self-change of smoking: toward an integrative model of change. J Consult Clin Psychol. 1983;51(3):390- 5. https:// doi.org/10.1037//0022-006x.51.3.390

9. Awaisu A, Mohamed MHN, Aziz NA, Sulaiman SAS, Noordin NM, Muttalif AR, et al. Tobacco use prevalence, knowledge, and attitudes among newly diagnosed tuberculosis patients in Penang State and Wilayah Persekutuan Kuala Lumpur, Malaysia. Tob Induc Dis. 2010;8(1):3. https://doi.org/10.1186/16179625-8-3

10. Meier KS. Tobacco Truths: The impact of role models on children's attitudes toward smoking. Health Educ Q. 1991;18(2):173-82. https://doi.org/10.1177/109019819101800203

11. Torabi MR, Yang J, Li J. Comparison of tobacco use knowledge, attitude and practice among college students in China and the United States. Health Promot Int. 2002;17(3):247-53. https://doi.org/10.1093/heapro/17.3.247

12. Wang J, Shen $\mathrm{H}$. Review of cigarette smoking and tuberculosis in China: intervention is needed for smoking cessation among tuberculosis patients. BMC Public Health. 2009;9(1):292. https://doi.org/10.1186/1471-2458-9-292

13. GBD 2017 Causes of Death Collaborators. Global, regional, and national age-sex-specific mortality for 282 causes of death in 195 countries and territories, 1980-2017: a systematic analysis for the Global Burden of Disease Study 2017. Lancet. 2018;392(10159):1736-88. https://doi.org/10.1016/S01406736(18)32203-7
14. Lienhardt C, Fielding K, Sillah JS, Bah B, Gustafson P, Warndorff $D$, et al. Investigation of the risk factors for tuberculosis: a case-control study in three countries in West Africa. Int J Epidemiol. 2005;34(4):914-23. https:// doi.org/10.1093/ije/dyi100

15. Gajalakshmi V, Peto R, Kanaka TS, Jha P. Smoking and mortality from tuberculosis and other diseases in India: retrospective study of 43000 adult male deaths and 35000 controls. Lancet. 2003;362(9383):507-15. https://doi.org/10.1016/ S0140-6736(03)14109-8

16. Aryanpur M, Masjedi MR, Hosseini M, Mortaz E, Tabarsi P, Soori $\mathrm{H}$, et al. Cigarette smoking in patients newly diagnosed with pulmonary tuberculosis in Iran. Int J Tuberc Lung Dis. 2016;20(5):679-84. https://doi.org/10.5588/ijtld.15.0662

17. Batista LAL, Albuquerque MFPMP, Ximenes RAA, Rodrigues LC. Smoking increases the risk of relapse after successful tuberculosis treatment. Int J Epidemiol. 2008;37(4):841-51. https://doi.org/10.1093/ije/dyn113

18. Santha T, Garg R, Frieden TR, Chandrasekaran V, Subramani R, Gopi PG, et al. Risk factors associated with default, failure and death among tuberculosis patients treated in a DOTS programme in Tiruvallur District, South India, 2000. Int J Tuberc Lung Dis. 2002;6(9):780-8. PMID: 12234133

19. Leung CC, Yew WW, Tam CM, Chan CK, Chang KC, Law WS, et al. Socio-economic factors and tuberculosis: a districtbased ecological analysis in Hong Kong. Int J Tuberc Lung Dis. 2004;8(8):958-64. PMID: 15305477

20. Masjedi MR, Hosseini M, Aryanpur M, Mortaz E, Tabarsi P, Soori $\mathrm{H}$, et al. The effects of smoking on treatment outcome in patients newly diagnosed with pulmonary tuberculosis. Int J Tuberc Lung Dis. 2017;21(3):351-6. https://doi.org/10.5588/ ijtld.16.0513

21. Dujaili JA, Sulaiman SAS, Awaisu A, Muttalif AR, Blebil AQ. Outcomes of tuberculosis treatment: a retrospective cohort analysis of smoking versus non-smoking patients in Penang, Malaysia. J Public Health. 2011;19(2):183-9. https://doi. org/10.1007/s10389-010-0365-3

22. El Sony A, Slama K, Salieh M, Elhaj H, Adam K, Hassan $A$, et al. Feasibility of brief tobacco cessation advice for tuberculosis patients: a study from Sudan. Int J Tuberc Lung Dis. 2007;11(2):150-5. PMID: 17263284

23. Ng N, Padmawati RS, Prabandari YS, Nichter M. Smoking behavior among former tuberculosis patients in Indonesia: intervention is needed. Int J Tuberc Lung Dis. 2008;12(5):56772. PMID: 18419894

24. Bissell K, Fraser T, Chen-Yuan C, Enarson DA. Smoking cessation and smokefree environments for tuberculosis patients. Second Edition 2010. Paris: International Union Against Tuberculosis and Lung Disease; 2010. Available from: https://theunion.org/ sites/default/files/2020-08/pub_smokingcessation_eng.pdf

25. Caraballo RS, Giovino GA, Pechacek TF, Mowery PD. Factors associated with discrepancies between self-reports on cigarette smoking and measured serum cotinine levels among persons aged 17 years or older: Third National Health and Nutrition Examination Survey, 1988-1994. Am J Epidemiol. 2001;153(8):807-14. https://doi.org/10.1093/aje/153.8.807 